Cochrane Database of Systematic Reviews

\title{
Medical and surgical abortion for women living with HIV (Review)
}

Saleem HT, Narasimhan M, Ganatra B, Kennedy CE

Saleem HT, Narasimhan M, Ganatra B, Kennedy CE.

Medical and surgical abortion for women living with HIV.

Cochrane Database of Systematic Reviews 2018, Issue 12. Art. No.: CD012834.

DOI: 10.1002/14651858.CD012834.pub2.

www.cochranelibrary.com 
ABSTRACT 1

PLAIN LANGUAGE SUMMARY

BACKGROUND

OBJECTIVES

METHODS

RESULTS

Figure 1.

DISCUSSION

AUTHORS' CONCLUSIONS

ACKNOWLEDGEMENTS

REFERENCES

CHARACTERISTICS OF STUDIES

APPENDICES

CONTRIBUTIONS OF AUTHORS

DECLARATIONS OF INTEREST

SOURCES OF SUPPORT

DIFFERENCES BETWEEN PROTOCOL AND REVIEW

NOTES

INDEX TERMS

\section{TABLE OF CONTENTS}


[Intervention Review]

\title{
Medical and surgical abortion for women living with HIV
}

\author{
Haneefa T Saleem ${ }^{1}$, Manjulaa Narasimhan², Bela Ganatra², Caitlin E Kennedy ${ }^{1}$
}

1Department of International Health, Social and Behavioral Interventions Program, Johns Hopkins Bloomberg School of Public Health, Baltimore, Maryland, USA. 2Department of Reproductive Health and Research, World Health Organization, Geneva, Switzerland

Contact: Haneefa T Saleem, Department of International Health, Social and Behavioral Interventions Program, Johns Hopkins Bloomberg School of Public Health, 615 N. Wolfe Street, Suite E5033, Baltimore, Maryland, 21205, USA. hsaleem1@jhu.edu.

Editorial group: Cochrane Fertility Regulation Group.

Publication status and date: New, published in Issue 12, 2018.

Citation: Saleem HT, Narasimhan M, Ganatra B, Kennedy CE. Medical and surgical abortion for women living with HIV. Cochrane Database of Systematic Reviews 2018, Issue 12. Art. No.: CD012834. DOI: 10.1002/14651858.CD012834.pub2.

Copyright @ 2018 The Cochrane Collaboration. Published by John Wiley \& Sons, Ltd.

\section{A B S T R A C T}

\section{Background}

The World Health Organization (WHO) guidelines for safe abortion recommend medical abortion with mifepristone and misoprostol or surgical abortion with vacuum aspiration or dilation and evacuation as safe and effective options for women. However, no specific clinical considerations are stipulated within these guidelines for women living with HIV. Concerns have been raised that women living with HIV may be at greater risk of adverse abortion outcomes compared to HIV-uninfected women due to immunosuppression, high rates of coinfection with other sexually transmitted infections, and possible contraindications between medications used for medical abortion and antiretroviral therapy regimens.

\section{Objectives}

Our primary objective was to assess the effectiveness and safety of medical versus surgical abortion among women living with HIV. Our secondary objectives were to: (1) compare outcomes of medical and surgical abortion between women living with HIV and women without HIV and (2) describe outcomes of medical and surgical abortion among women living with HIV.

\section{Search methods}

We conducted our search on 17 April 2018. We searched for all published and unpublished trials and observational studies of medical and surgical abortion among women living with HIV. We searched the Cochrane Central Register of Controlled Trials (CENTRAL), MEDLINE, Embase, PsycINFO, CINAHL, ClinicalTrials.gov, and the WHO International Clinical Trials Registry Platform using a combination of terms for abortion and HIV. We searched conference websites for relevant abstracts. We also sought unpublished data stratified by HIV status that could be newly analyzed.

\section{Selection criteria}

We considered randomized controlled trials (RCTs), non-RCTs, and observational studies. We considered: (1) studies on the effectiveness and safety of medical versus surgical abortion among women living with HIV; (2) studies comparing outcomes of abortion for both methods between women living with HIV and women without HIV; and (3) studies that described outcomes of abortion among women living with HIV.

\section{Data collection and analysis}

One review author screened the titles, abstracts, citation information, and descriptor terms for citations initially identified by the search. We obtained the full-text articles of all potentially eligible studies when these were available. Two review authors independently examined the full-text articles for compliance with the inclusion criteria and determination of final study selection. We planned to conduct metaanalysis if a sufficient number of studies (at least three) addressed the same research question and presented data on sufficiently comparable outcomes. 


\section{Main results}

Of 3840 records screened, we identified just one conference abstract that met our inclusion criteria. This prospective cohort study assessed the efficacy and acceptability of home administration of misoprostol for early medical abortion among women living with HIV who were of less than 63 days amenorrhea in Ukraine. Medical abortion was effective in 65 of 68 cases (96\%) examined. The small number of failures included incomplete abortion $(n=1)$, heavy bleeding $(n=1)$, and ongoing pregnancy $(n=1)$. There were no serious infections.

\section{Authors' conclusions}

Due to the paucity of studies, we were unable to determine if outcome differences exist between women living with HIV and women without HIV who undergo medical or surgical abortion. We found no evidence suggesting that medical or surgical abortions are unsafe for women living with HIV. While additional research would strengthen the evidence base, healthcare providers should not be deterred from providing access to safe abortion to their patients living with HIV.

\section{PLAIN LANGUAGE SUMMARY}

\section{Medical and surgical abortion for women living with HIV}

\section{Review question}

We reviewed the evidence regarding the safety and success of medical and surgical abortion among women living with HIV. Our main question was: Are there differences in the safety and success of medical abortion versus surgical abortion for women living with HIV? Our secondary questions were: (1) Do outcomes of medical and surgical abortion differ between women living with HIV and women without HIV?; and (2) What outcomes of medical and surgical abortion have been reported for women living with HIV?

\section{Background}

The World Health Organization (WHO) guidelines for safe abortion recommend medical abortion with mifepristone and misoprostol or surgical abortion with vacuum aspiration or dilation and evacuation as safe and successful options for women. However, the guidelines make no specific clinical considerations for women living with HIV.

\section{Study characteristics}

The evidence is current to 17 April 2018. Of the 3840 records screened, we identified only one unpublished study that met our inclusion criteria. The intervention focused on women living in Ukraine with HIV undergoing medical abortion at home.

\section{Key results}

The quality of evidence was low, but found that medical abortion was successful with no major complications experienced among women living with HIV.

\section{Quality of the evidence}

The results from this review do not provide enough evidence to determine if differences exist in abortion outcomes for women living with HIV, but also no evidence was found showing that abortion is unsafe in this population. As it is important for all women to have access to safe abortion to combat the public health threat of high rates of maternal deaths, healthcare providers should not be deterred from providing access to safe abortion to their patients living with HIV. 


\section{B A C K G R O U N D}

\section{Description of the condition}

The World Health Organization (WHO) guidelines for safe abortion recommend medical interventions for abortion with mifepristone and misoprostol or surgical interventions for the termination of pregnancy with vacuum aspiration or dilation and evacuation (the latter for pregnancies greater than 12 to 14 weeks) as safe and effective options (WHO 2012). However, the guidelines make no specific clinical considerations for women living with HIV. Studies have demonstrated no postoperative differences following obstetric surgery in women living with HIV, but it is unclear if this is true in terms of abortion care (Cavasin 2009; Sekirime 2009). Additionally, vomiting from drugs used for medical abortion could also reduce the efficacy of antiretroviral drugs for HIV treatment (de Bruyn 2003). Hospitalization, hemorrhage requiring blood transfusion, and major operative interventions resulting from abortion complications could also add increased risk, stress, and costs to women living with HIV undergoing an abortion.

\section{Description of the intervention}

We defined medical and surgical abortion according to the WHO Safe Abortion Guidelines (WHO 2012):

1. medical abortion methods: use of pharmacological drugs to terminate pregnancy. The terms 'non-surgical abortion' or 'medication abortion' are also used;

2. surgical abortion methods: use of transcervical procedures for terminating pregnancy, including vacuum aspiration and dilation and evacuation.

We considered medical and surgical abortion up to 28 weeks of gestation.

\section{How the intervention might work}

Manski and colleagues conducted a systematic review of clinical outcomes of surgical and medical abortion among women living with HIV (Manski 2012). Searching for peer-reviewed articles published through 2011, they found few studies on surgical abortion and no studies on medical abortion among this population. The studies identified mostly covered illegal or nonspecified abortion, which may or may not have met WHO Safe Abortion Guidelines (WHO 2012), but suggested no significant differences in complications by HIV status. Manski and colleagues also reviewed data from gynecological procedures that were similar to or more invasive than abortion, and again found no differences in complications by HIV status. Finally, they reviewed data on changes in hemoglobin levels due to blood loss from medical abortion, where anemia is prevalent, and frequency and duration of vomiting due to medical abortion drugs; both analyses suggested these were relatively minor concerns. The Manski 2012 review concluded based on the limited available data that both medical and surgical abortions are safe and appropriate for women living with HIV.

\section{Why it is important to do this review}

In order to inform an update of the WHO's 'Safe abortion: technical and policy guidance for health systems,' which will include guidance on women living with HIV, and the development of WHO consolidated guidelines on sexual and reproductive health and the rights of women living with HIV (WHO 2012; WHO 2017); and to build upon the global community survey on the sexual and reproductive health priorities of women living with HIV (Salamander Trust 2014), we sought to expand the work in Manski 2012 by:

1. updating the search using a rigorous systematic review process (Higgins 2011);

2. searching conference abstracts and trial registries (in addition to peer-reviewed articles);

3. searching for articles in languages other than English; and

4. contacting authors to identify unpublished data sets with information on both abortion outcomes and HIV that could potentially be used to examine whether medical and surgical abortion is effective and safe for women living with HIV.

\section{O B J E C T I VES}

Our primary objective was to assess the effectiveness and safety of medical versus surgical abortion among women living with HIV. Our secondary objectives were to: (1) compare outcomes of medical and surgical abortion between women living with HIV and women without HIV and (2) describe outcomes of medical and surgical abortion among women living with HIV.

\section{METHODS}

\section{Criteria for considering studies for this review}

\section{Types of studies}

We included randomized controlled trials (RCTs), non-RCTs, and observational (e.g. cohort) studies. Per our objectives, we included:

1. studies on the effectiveness and safety of medical versus surgical abortion among women living with HIV;

2. studies comparing outcomes of medical or surgical abortion or both between women living with HIV and women without HIV; and

3. studies that describe outcomes of medical or surgical abortion or both among women living with HIV.

\section{Types of participants}

Pregnant women living with HIV (with known HIV status) and women without HIV seeking abortion services, compliant with WHO clinical practice guidelines for safe abortions (WHO 2012).

\section{Types of interventions}

Medical and surgical abortion, as defined by the WHO Safe Abortion Guidelines (WHO 2012):

1. medical abortion methods: use of pharmacological drugs to terminate pregnancy. The terms 'non-surgical abortion' or 'medication abortion' are also used.

2. surgical abortion methods: use of transcervical procedures for terminating pregnancy, including vacuum aspiration and dilation and evacuation.

We considered medical and surgical abortion up to 28 weeks of gestation. 


\section{Types of outcome measures}

\section{Primary outcomes}

1. Efficacy (complete abortion, i.e. without need for surgical evacuation).

2. Serious adverse events:
a. death;
b. hospitalization;
c. hemorrhage requiring blood transfusion;
d. major operative intervention (e.g. laparotomy).

\section{Secondary outcomes}

1. Other adverse outcomes and side effects:

a. hemorrhage not requiring blood transfusion;

b. vomiting;

c. infection.

2. Patient satisfaction, assessed using a validated survey questionnaire, such as the Patient Satisfaction Questionnaire-18 (PSQ-18), Marshall 1994, or Treatment Satisfaction Questionnaire for Medication (TSQM) (Atkinson 2004).

\section{Search methods for identification of studies}

We searched for all published and unpublished trials and observational studies of medical and surgical abortion among pregnant women living with HIV seeking services for the termination of pregnancy, irrespective of when they received their HIV diagnosis and irrespective of CD4 count or other health status measures, without restrictions based on language or intervention location.

\section{Electronic searches}

We searched the following electronic databases for relevant studies.

1. The Cochrane Central Register of Controlled Trials (CENTRAL) (via Cochrane Register of Studies Online (CRSO)) (from inception to 17 April 2018) (Appendix 1).

2. MEDLINE Ovid (1946 to 17 April 2018) (Appendix 2).

3. Embase Ovid (1980 to 17 April 2018) (Appendix 3).

4. PsycINFO Ovid (1806 to 17 April 2018) (Appendix 4).

5. CINAHL (Cumulative Index to Nursing and Allied Health Literature) EBSCO (from 1961 to 17 April 2018) (Appendix 5).

6. WHO International Clinical Trials Registry Platform (WHO ICTRP) (www.who.int/ictrp; to 27 December 2017) (Appendix 6).

7. US National Institutes of Health Ongoing Trials Register ClinicalTrials.gov (www.clinicaltrials.gov; to 27 December 2017) (Appendix 6).

The MEDLINE search was combined with the Cochrane Highly Sensitive Search Strategy for identifying randomized trials described in the Cochrane Handbook for Systematic Reviews of Interventions (Higgins 2011).

The Embase and CINAHL searches are combined with trial filters developed by the Scottish Intercollegiate Guidelines Network (SIGN) (www.sign.ac.uk/search-filters.html).
The PsycINFO search filter was developed by Health Information research unit - McMaster University (hiru.mcmaster.ca/hiru/ HIRU_Hedges_PsycINFO_Strategies.aspx).

Our search strategies used combinations of terms for abortion and HIV.

\section{Searching other resources}

In order to obtain additional data, we conducted secondary reference searches on all included studies, as well as the Manski 2012 review.

We handsearched the following conference websites for available abstracts: International AIDS Conference (IAC); IAS Conference on HIV Pathogenesis, Treatment, and Prevention (IAS); the Conference on Retroviruses and Opportunistic Infections (CROI); the International Conference on AIDS and STIs in Africa (ICASA); International Federation of Gynecology and Obstetrics (FIGO) World Conference; and the American Congress of Obstetricians and Gynecologists (ACOG).

We also searched for unpublished studies, existing cohort studies, and trials that might have collected data on medical or surgical abortion outcomes and HIV status, but had not analyzed their data by HIV status. To identify such studies, we reviewed the reference lists of two systematic reviews on abortion outcomes (Kulier 2011; Say 2005). We contacted the corresponding authors to see if they could disaggregate their data on abortion outcomes by HIV status of participants. We also asked these experts to identify any additional studies that we may have missed.

\section{Data collection and analysis}

\section{Selection of studies}

One review author (HTS or CEK) screened titles, abstracts, citation information, and descriptor terms of citations initially identified by the search. We obtained the full-text articles of all studies deemed potentially eligible. Two review authors (HTS, CEK) independently examined the full-text articles for compliance with the inclusion criteria and determination of final study selection. Any differences were resolved through consensus. We have documented this selection process in a PRISMA flow chart (Moher 2009).

\section{Data extraction and management}

Two review authors (HTS, CEK) planned to independently extract data using standardized data extraction forms, resolving any differences through consensus. Using these forms we collected information available on study objectives; location; population characteristics (including time since HIV diagnosis, CD4 count/ HIV clinical stage, antiretroviral and other related treatment/ medication use, gestational age and/or trimester, and abortion history); abortion method; study design; sample size; followup periods; loss to follow-up; analytic approach; outcome measures; number of participants in each comparison group; effect sizes; confidence intervals; significance levels; conclusions; and limitations.

We attempted to contact study authors when insufficient information was presented on methods or results or both. 


\section{Assessment of risk of bias in included studies}

For RCTs, two review authors (HTS, CEK) planned to assess the risk of bias using the Cochrane tool for assessing risk of bias (Higgins 2011). This tool assesses random sequence generation (selection bias), allocation concealment (selection bias), blinding of participants and personnel (performance bias), blinding of outcome assessment (detection bias), incomplete outcome data (attrition bias), and selective reporting (reporting bias). We assessed and classified methodological components of the studies as low, high, or unclear risk of bias. Examples of study elements that could have constituted high risk of bias included: differences in how outcomes were measured or determined, particularly for subjective measures, such as patient satisfaction; non-reporting of insignificant differences in outcomes between comparison groups (even if measured in the original study); differences in how abortion services were provided, particularly if health providers became aware of the HIV status of their patients from physical markers; and others. We assessed studies that did not explicitly state that abortion procedures followed WHO Safe Abortion Guidelines as at high risk of other bias (WHO 2012). For observational studies using different designs, we used an adapted version of the NewcastleOttawa scale to assess study quality (Wells 2009).

\section{Measures of treatment effect}

We considered all effect measures reported by individual studies; outcome measures were not part of the inclusion criteria for the review. Measures of treatment effect could include risk ratios, odds ratios, mean difference, prevalence, or simple descriptive statistics. If sufficient, comparable outcome data existed to conduct meta-analysis for any of the primary or secondary outcomes, we would start our analysis with fixed-effect models. Since our primary outcomes were biological, we anticipated the same underlying mechanism across studies. However, if we detected high heterogeneity, we would shift to a random-effects meta-analysis and potentially present both analyses, to include Mantel-Haenszel odds ratios and 12 statistics to assess heterogeneity. We planned to follow Cochrane suggestions for thresholds for 12 (Higgins 2011): $0 \%$ to $40 \%$ might not be important; $30 \%$ to $60 \%$ may represent moderate heterogeneity; $50 \%$ to $90 \%$ may represent substantial heterogeneity; $75 \%$ to $100 \%$ is considerable heterogeneity.

\section{Unit of analysis issues}

If we identified RCTs, we planned to consider the unit of analysis as 'per woman randomized.' Given the nature of the intervention, we did not anticipate cross-over designs or cluster-randomized trials. If individual studies presented repeated observations for participants (in this case, multiple pregnancies for an individual woman), we planned to include only the first instance of termination of pregnancy for each participant and conduct separate analyses on second, third, and fourth pregnancies.

\section{Dealing with missing data}

We attempted to contact the study authors to obtain more information if we identified missing data. As data allowed, we planned to consider sensitivity analyses to remove studies with significant amounts of missing data. For studies in which data were missing or incomplete, we reported the findings as 'unclear risk,' or 'high risk' when the missing data pointed to potential risk of bias, for example if a study was missing data on outcome assessment. We documented our reasons for these final judgements.

\section{Assessment of heterogeneity}

We planned to assess heterogeneity in meta-analyses using the 12 statistic.

\section{Assessment of reporting biases}

Because detecting and correcting for publication bias and other reporting biases is difficult, we minimized their potential impact by doing a comprehensive search for both published and unpublished studies and contacted authors for datasets that might be used to answer the research questions. We considered using funnel plots to assess reporting bias if 10 or more eligible studies were included in the review.

\section{Data synthesis}

We analyzed data by aim and by outcome as data permitted using Review Manager 5 software (RevMan 2014). We did not conduct a meta-analysis as we were unable to identify a sufficient number of studies (at least three) that addressed the same research question and presented data on sufficiently comparable outcomes. We would combine effect sizes in odds ratios using the MantelHaenszel method in meta-analysis.

\section{Subgroup analysis and investigation of heterogeneity}

We were unable to conduct subgroup analyses based on world region and country income group (according to World Bank country classifications of low-, lower-middle-, upper-middle-, and highincome countries) as planned as the search yielded limited data (World Bank 2017).

\section{Sensitivity analysis}

Given the limited data available, we did not conduct sensitivity analyses.

\section{Overall quality of the body of evidence: 'Summary of findings' table}

We planned to prepare two 'Summary of findings' tables using GRADEpro GDT and Cochrane methods (GRADEpro GDT 2015; Guyatt 2008). The first table would evaluate the overall quality of the body of evidence for the primary and secondary outcomes, including all adverse events, comparing women living with HIV to women without HIV who have had either a medical or surgical abortion. The second table would evaluate the overall quality of the body of evidence for primary and secondary outcomes of medical versus surgical abortions among women living with HIV. We planned to assess the quality of the evidence using GRADE criteria: risk of bias, consistency of effect, imprecision, indirectness, and publication bias. Two review authors (HTS, CEK) would independently assess evidence quality (high, moderate, low, or very (ow), resolving any disagreements by discussion. We would justify, document, and incorporate judgements into the reporting of results for each outcome.

We planned to extract study data, format our comparisons in Data and analyses tables, and prepare a 'Summary of findings' table before writing the results and conclusions of our review. 


\section{RESULTS}

\section{Description of studies}

\section{Results of the search}

We searched PubMed MEDLINE, Embase, PsycINFO, and CINAHL databases. We searched for completed and ongoing randomized trials through the Cochrane Central Register of Controlled Trials (CENTRAL), WHO ICTRP, and ClinicalTrials.gov. We also searched conference websites for relevant abstracts. For the IAC, IAS, and CROI online abstract archives, we searched for the term 'abortion.' For the FIGO and ACOG online abstract archives, we searched for HIV. We were unable to find online archives of abstracts for ICASA.
Our search yielded 4774 records identified through the online database search, an additional 415 records identified through the online conference abstract search, and five records identified through other sources (three from reference lists, one from ClinicalTrials.gov, and one from WHO ICTRP) (Figure 1). After removal of duplicate records, 3840 records remained; 3826 of these were excluded after screening of titles and abstracts (Figure 1). Two review authors (HTS, CEK) screened the remaining 14 records (nine peer-reviewed articles, four conference abstracts, and one clinical trial record). Outreach to multiple authors yielded no unpublished studies or additional data that could be used to address our primary and secondary objectives. 
Figure 1. Study flow diagram.

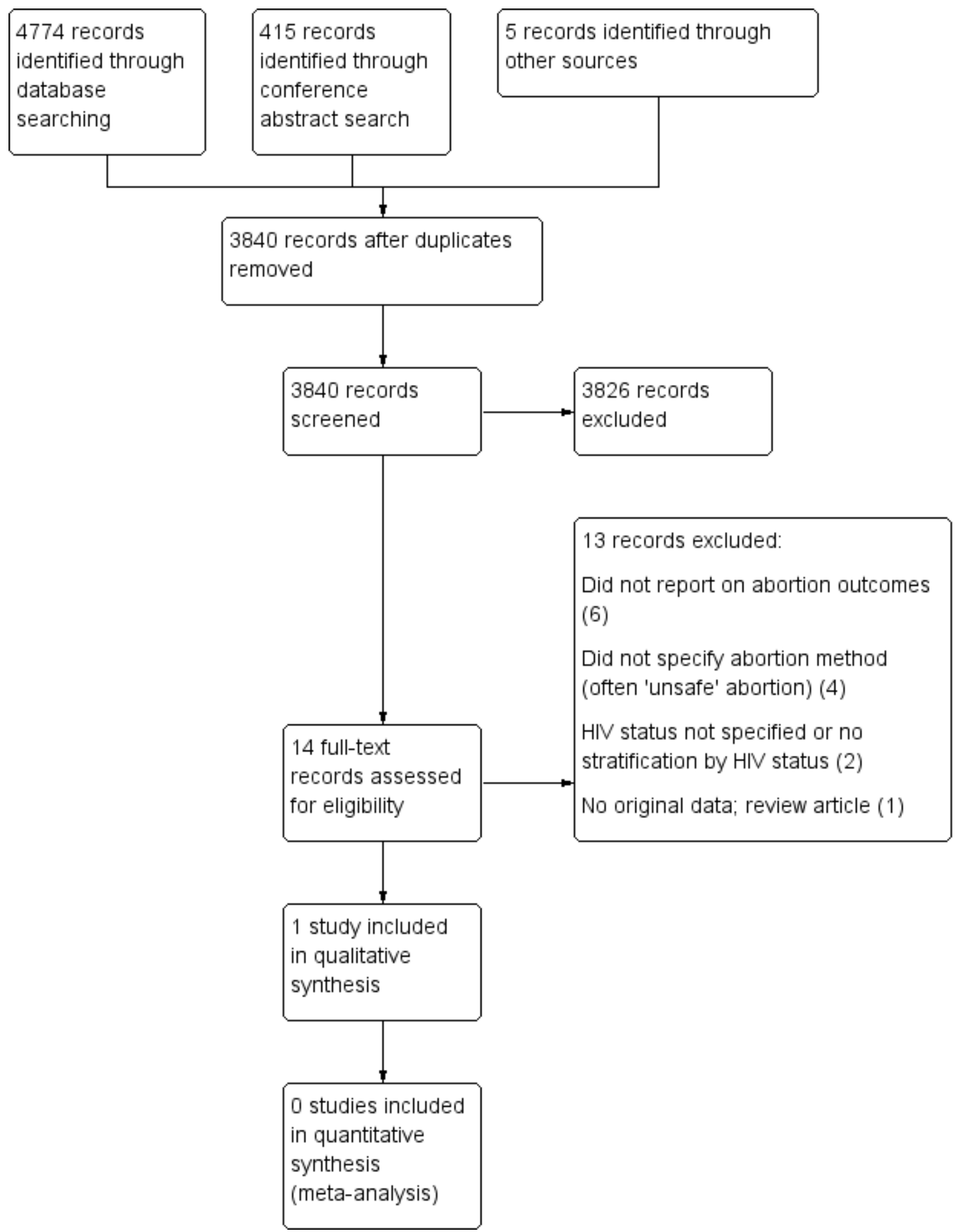




\section{Included studies}

Ultimately, only one prospective cohort study in the form of a conference abstract was eligible for inclusion (Posokhova 2012). The intervention focused on women living in Ukraine with HIV undergoing medical abortion up to 63 days amenorrhea at home. We contacted the study author to obtain additional information on the actual regimen used for medical abortion (mifepristone $200 \mathrm{mg}$ orally in the hospital and misoprostol $400 \mathrm{mcg}$ sublingually 36 to 48 hours later).

\section{Excluded studies}

We excluded 13 records after full-text review. Six of these records did not report on abortion outcomes (Agwu 2011; Ammassari 2013; Birungi 2011; Blood 2009; Coll 2011; Para 2010). Four records did not specify an abortion method, or the focus was on the management of complications from spontaneous or induced unsafe abortions (Grubert 2002; Okong 2002; Othieno 2015; Stuart 2004). One record did not specify the HIV status of study participants (Mitchell 2010). Another record reported on medical abortion outcomes and reported the HIV status of participants, but did not stratify outcome data by HIV status and had a very small number of HIV-positive participants (only four) (Pongsatha 2011). One record, a conference abstract, was a review and did not include original data (Blanchard 2012).

\section{Risk of bias in included studies}

Posokhova 2012 assessed the efficacy and acceptability of home administration of misoprostol for medical abortion among 68 women living with HIV. The authors did not describe the sampling strategy. The study sample included women living with HIV who were not receiving antiretroviral therapy with amenorrhea up to 63 days seeking an early medical abortion at a hospital in Ukraine.

\section{Allocation}

Unable to assess.

\section{Blinding}

Unable to assess.

\section{Incomplete outcome data}

Unable to assess.

\section{Selective reporting}

Unable to assess.

\section{Other potential sources of bias}

Posokhova 2012 did not report on how the study team confirmed that participants followed instructions for home administration of misoprostol. However, when contacted directly for additional information, the study author stated that they were able to confirm home administration of misoprostol.

\section{Effects of interventions}

In Posokhova 2012, of the 68 women living with HIV included in the study who were not on antiretroviral therapy examined, medical abortion was found to be successful, that is complete, in 65 (96\% of) cases. The small number of failures included incomplete abortion $(n=1)$, heavy bleeding $(n=1)$, and ongoing pregnancy $(n=1)$.
There were no cases of serious infections. The authors concluded that medical abortion administered at home is a safe and effective alternative to surgical abortion for women living with HIV due to the high rate of success and minimal complications observed among study participants.

\section{DISCUSSION}

\section{Summary of main results}

Due to the paucity of studies, we are unable to determine if outcome differences exist in women living with HIV or as compared to women without HIV who undergo medical or surgical abortion. Only one conference abstract met our inclusion criteria, and no existing datasets could be used for new analyses on this topic. On the other hand, we found no evidence suggesting that medical or surgical abortions are unsafe for women living with HIV.

\section{Overall completeness and applicability of evidence}

This review provides neither evidence for or against the existence of outcome differences in women living with HIV undergoing medical or surgical abortion or in comparison to women without HIV. Although reassuring in its results, the one included study was assessed as of low quality due to its non-randomized study design and our inability to assess risk of bias (Posokhova 2012).

\section{Quality of the evidence}

The extent of the evidence was severely limited, and the quality of evidence was low and unable to be assessed for risk of bias. Due to legal restrictions on abortion and stigmatization of HIV and abortion in many contexts, intervention studies on this topic are rare, with the one study identified being observational. Despite these limitations, there are several strengths to this review that should be highlighted in comparison to the previous review published on a similar topic (Manski 2012). We searched extensively for conference abstracts and articles/abstracts in all languages. We also contacted numerous authors to search for unpublished data in the form of cohort or other studies, including studies that may have included data that could be used to address this topic, even if the original research question was different.

There has been some discussion that women living with HIV may be at increased risk of complications from abortion due to immunosuppression, high rates of co-infection with other sexually transmitted infections and anemia, and possible contraindications between medications used for medical abortion and antiretroviral therapy (de Bruyn 2005; Nascimento 2012). The dearth of evidence on whether the risks and outcomes of medical and surgical abortion among women living with HIV differ from women without HIV, or on outcomes of medical versus surgical abortion among women living with HIV, limits evidence-based policymaking. However, despite limited research, there is no clear reason to doubt that both medical and surgical abortions are safe and effective for women living with HIV, and either option can be considered for this population.

Legal restrictions on abortions in many low- and middle-income countries where HIV is prevalent likely contribute to the lack of research on abortion outcomes among women living with HIV. Of the 13 peer-reviewed articles excluded from our review after full-text assessment, three reported on studies conducted in countries where abortion is legally restricted except under strict 
circumstances, and where unsafe abortion contributes to high rates of maternal death (Birungi 2011; Okong 2002; Othieno 2015). Women living with HIV have been shown to be more likely to have an unsafe, induced abortion compared to women without HIV (Pilecco 2014). This is particularly troubling since women living with HIV may face more severe complications from unsafe abortion than women without HIV (de Bruyn 2003; Delvaux 2007). In one study screened for the review that was conducted in Uganda, the authors found that women living with HIV had similar odds of having complications from an incomplete abortion as HIV-negative women (Othieno 2015). However, women who did not know their HIV status had greater odds of having complications from an incomplete abortion compared to women without HIV (Othieno 2015). It is likely that some of these women were also HIV-positive, but unaware of their status.

Limited access to contraception, HIV-related stigma that leads partners, families, and even healthcare providers to disapprove of women living with HIV having children, economic constraints, fear of infecting one's child, and fear of one's ability to care for one's children have all been reported as contributing to the desires of women living with HIV to seek abortion care (Maccarthy 2014; Orner 2011). All women, including women living with HIV, have the right to comprehensive sexual and reproductive health services that meet their needs. For women living with HIV who desire an abortion as a result of socio-structural vulnerabilities or other reasons, the findings from this review highlight the need to ensure that they have access to safe, legal abortion.

\section{Potential biases in the review process}

Not applicable.

\section{Agreements and disagreements with other studies or reviews}

Similar to our review, the Manski 2012 review found very few studies examining outcomes of surgical and medical abortion among women living with HIV. However, the limited data available suggest that abortion is effective and safe for women living with HIV.

\section{AUTHORS' CONCLUSIONS}

\section{Implications for practice}

While the existing evidence is limited, we found no evidence to suggest that medical and surgical abortions are unsafe and ineffective for women living with HIV. The medical and public health communities should work together to remove barriers and expand access to safe, legal medical and surgical abortions for all women, including women living with HIV.

\section{Implications for research}

Future research should report on outcomes following medical and surgical abortion comparing women living with HIV to HIVnegative women. In 2016, the World Health Organization convened a Guideline Development Group (GDG), which included women living with HIV, to develop new evidence-based recommendations on sexual and reproductive health and rights of women living with HIV (WHO 2017), as well as to identify key research gaps (Siegfried 2017). During the meeting, the GDG recommended that national or global abortion registries with anonymized data compare outcomes of abortion between women living with HIV and women without HIV. National abortion registries, or a global abortion registry, would illuminate whether reasons for, and consequences of, medical and surgical abortion differ for women living with HIV. An abortion registry would also allow us to monitor and evaluate whether abortion services are equitably accessible to women regardless of HIV status. Other future relevant research areas identified by the GDG included healthcare providers' attitudes, knowledge and practices regarding the provision of abortion services to women living with HIV, and barriers and facilitators to accessing abortion services for women living with HIV. These future research areas were proposed in response to reports that women living with HIV continue to experience stigma and discrimination when accessing sexual and reproductive health services (Salamander Trust 2014).

Yet while additional research would strengthen the evidence base for future guidelines, healthcare providers should not be deterred from providing access to safe abortion to their patients living with HIV.

\section{ACKNOWLEDGEMENTS}

We wish to thank the Cochrane Fertility Regulation Group, and Marian Showell for her help in developing the search strategy and running database searches. We also thank Ping Teresa Yeh for her help searching for conference abstracts and clinical trials; Johns Hopkins Welch Library Informationists Peggy Gross, Claire Twose, and Christian Minter for their help in developing the original search strategy; and Nandi Siegfried for her review and comments on the draft manuscript. 


\section{RE F E R E N C E S}

\section{References to studies included in this review}

Posokhova 2012 \{published and unpublished data\} Posokhova S, Shevchenko S, Gumenyuk L, Nikolaeva T, Popova T. The experience of use of medical abortion for HIVpositive women at home in Ukraine. 19th International AIDS Conference; 201207 22-27; Washington, DC. 2012.

\section{References to studies excluded from this review}

Agwu 2011 \{published data only\}

Agwu AL, Jang SS, Korthuis PT, Araneta MR, Gebo KA, Agwu AL, et al. Pregnancy incidence and outcomes in vertically and behaviorally HIV-infected youth. JAMA 2011;305(5):468-70.

\section{Ammassari 2013 \{published data only\}}

Ammassari A, Cicconi P, Ladisa N, Sora F, Bini T, Trotta M, et al. Induced first abortion rates before and after HIV diagnosis: results of an Italian self-administered questionnaire survey carried out in 585 women living with HIV. HIV Medicine 2013;14(1):31-9.

\section{Birungi 2011 \{published data only\}}

Birungi $\mathrm{H}$, Obare F, van der Kwaak A, Namwebya JH. Maternal health care utilization among HIV-positive female adolescents in Kenya. International Perspectives on Sexual \& Reproductive Health 2011;37(3):143-9.

\section{Blanchard 2012 \{unpublished data only\}}

Blanchard K, Manski R, Dennis A, Grossman D. Early abortion for HIV+ women-is there a preferred method?. International Journal of Gynecology and Obstetrics. 20th FIGO World Congress of Gynecology and Obstetrics; 201210 07-12; Rome, Italy. 2012.

\section{Blood 2009 \{published data only\}}

Blood E, Beckwith C, Bazerman L, Cu-Uvin S, Mitty J. Pregnancy among HIV-infected refugees in Rhode Island. AIDS Care 2009;21(2):207-11.

\section{Coll 2011 \{published data only\}}

Coll O, Lonca M, Lopez M, Gonce A, Hernandez S, Palacio M, et al. Termination of pregnancy among HIV-infected women in the era of HAART. American Journal of Obstetrics and Gynecology 2011;204 (1 suppl):S253.

\section{Grubert 2002 \{published data only\}}

Grubert TA, Reindell D, Kastner R, Belohradsky BH, Gurtler L, Stauber M, et al. Rates of postoperative complications among human immunodeficiency virus-infected women who have undergone obstetric and gynecologic surgical procedures. Clinical Infectious Diseases 2002;34:822-30.

\section{Mitchell 2010 \{published data only\}}

Mitchell EM, Kwizera A, Usta M, Gebreselassie H. Choosing early pregnancy termination methods in Urban Mozambique. Social Science \& Medicine 2010;71(1):62-70.
Okong 2002 \{published data only\}

Okong P, Biryahwaho B, Bergstrom S. Post-abortion endometritis-myometritis and HIV infection. International Journal of STD \& AIDS 2002;13:729-32.

Othieno 2015 \{published data only\}

Othieno C, Babigumira JB, Richardson B. Are women with complications of an incomplete abortion more likely to be HIV infected than women without complications?. BMC Women's Health 2015;15:95.

\section{Para 2010 \{published data only\}}

Para MF, Schouten J, Rosenkranz SL, Yu S, Weiner D, Tebas P, et al. Phase I/II trial of the anti-HIV activity of mifepristone in HIV-infected subjects ACTG 5200. Journal of Acquired Immune Deficiency Syndrome 2010;53(4):491-5.

Pongsatha 2011 \{published data only\}

Pongsatha S, Tongsong T. Outcomes of pregnancy termination by misoprostol at 14-32 weeks of gestation: a 10-year experience. Journal of the Medical Association of Thailand 2011;94:897-901.

\section{Stuart 2004 \{published data only\}}

Stuart GS, Sheffield JS, Hill JB, McIntire DD, McElwee B, Wendel GD. Morbidity that is associated with curettage for the management of spontaneous and induced abortion in women who are infected with HIV. American Journal of Obstetrics and Gynecology 2004;191:993-7.

\section{Additional references}

\section{Atkinson 2004}

Atkinson MJ, Sinha A, Hass SL, Colman SS, Kumar RN, Brod M, et al. Validation of a general measure of treatment satisfaction, the Treatment Satisfaction Questionnaire for Medication (TSQM), using a national panel study of chronic disease. Health and Quality of Life Outcomes 2004;2(1):12.

\section{Cavasin 2009}

Cavasin H, Dola T, Uribe O, Biswas M, Do M, Bhuiyan A, et al. Postoperative infectious morbidities of Cesarean delivery in human immunodeficiency virus-infected women. Infectious Diseases in Obstetrics and Gynecology 2009;2009:827405.

\section{de Bruyn 2003}

de Bruyn M. Safe abortion for HIV-positive women with unwanted pregnancy: a reproductive right. Reproductive Health Matters 2003;11(22):152-61.

\section{de Bruyn 2005}

de Bruyn M. HIV/AIDS and Reproductive Health-Sensitive and Neglected Issues: a Review of the Literature, Recommendations for Action. Chapel Hill: Ipas, 2005. 


\section{Delvaux 2007}

Delvaux T, Nostlinger C. Reproductive choice for women and men living with HIV: contraception, abortion and fertility. Reproductive Health Matters 2007;15:46-66.

\section{GRADEpro GDT 2015 [Computer program]}

McMaster University (developed by Evidence Prime). GRADEpro GDT. Hamilton (ON): McMaster University (developed by Evidence Prime), 2015.

\section{Guyatt 2008}

Guyatt GH, Oxman AD, Vist G, Kunz R, Falck-Ytter Y, AlonsoCoello P, et al. GRADE Working Group. GRADE: an emerging consensus on rating quality of evidence and strength of recommendations. BMJ 2008;336(7650):924-6.

\section{Higgins 2011}

Higgins JP, Green S, editor(s). Cochrane Handbook for Systematic Reviews of Interventions Version 5.1.0 (updated March 2011). The Cochrane Collaboration, 2011. Available from handbook.cochrane.org.

\section{Kulier 2011}

Kulier R, Kapp N, Gulmezoglu AM, Hofmeyr GJ, Cheng L, Campana A. Medical methods for first trimester abortion. Cochrane Database of Systematic Reviews 2011, Issue 11. [DOI: 10.1002/14651858.CD002855.pub4]

\section{Maccarthy 2014}

Maccarthy S, Rasanathan JJ, Crawford-Roberts A, Dourado I, Gruskin S. Contemplating abortion: HIV-positive women's decision to terminate pregnancy. Culture, Health \& Sexuality 2014;16:190-201.

\section{Manski 2012}

Manski R, Dennis A, Blanchard K, Lince N, Grossman D. Bolstering the evidence base for integrating abortion and HIV care: a literature review. AIDS Research and Treatment 2012;2012:802389.

\section{Marshall 1994}

Marshall GN, Hays RD. Patient Satisfaction Questionnaire Short Form (PSQ-18). Santa Monica: RAND, 1994.

\section{Moher 2009}

Moher D, Liberati A, Tetzlaff J, Altman DG. Preferred reporting items for systematic reviews and meta-analyses: The PRISMA statement. Annals of Internal Medicine 2009;151(4):264-9.

\section{Nascimento 2012}

Nascimento FG, Tanaka PY. Thrombocytopenia in HIV-infected patients. Indian Journal of Hematology and Blood Transfusion 2012;28(2):109-11.

\section{Orner 2011}

Orner PJ, de Bruyn M, Barbosa RM, Boonstra H, Gatsi-Mallet J, Cooper DD. Access to safe abortion: building choices for women living with HIV and AIDS. Journal of the International AIDS Society 2011;14:54.

\section{Pilecco 2014}

Pilecco FB, Teixeira LB, Vigo A, Dewey ME, Knauth DR. Lifetime induced abortion: a comparison between women living and not living with HIV. PLOS ONE 2014;9:e95570.

\section{RevMan 2014 [Computer program]}

Nordic Cochrane Centre, The Cochrane Collaboration. Review Manager 5 (RevMan 5). Version 5.3. Copenhagen: Nordic Cochrane Centre, The Cochrane Collaboration, 2014.

\section{Salamander Trust 2014}

Salamander Trust. Building a safe house on firm ground: key findings from a global values and preferences survey regarding the sexual and reproductive health of women living with HIV. salamandertrust.net/wp-content/uploads/2016/09/ BuildingASafeHouseOnFirmGroundFINALreport190115.pdf (accessed prior to 15 November 2018).

\section{Say 2005}

Say L, Kulier R, Gulmezoglu M, Campana A. Medical versus surgical methods for first trimester termination of pregnancy. Cochrane Database of Systematic Reviews 2005, Issue 1. [DOI: 10.1002/14651858.CD003037.pub2]

\section{Sekirime 2009}

Sekirime WK, Lule JC. Outcome of cesarean section in asymptomatic HIV-1 infection in Kampala, Uganda. Journal of Obstetrics and Gynaecology Research 2009;35(4):679-88.

\section{Siegfried 2017}

Siegfried N, Narasimhan M, Kennedy CE, Welbourn A, Yuvraj A. Using GRADE as a framework to guide research on the sexual and reproductive health and rights (SRHR) of women living with HIV-methodological opportunities and challenges. AIDS Care 2017;29(9):1088-93.

\section{Wells 2009}

Wells GA, Shea B, O'Connell D, Peterson J, Welch V, Losos M, et al. The Newcastle-Ottawa Scale (NOS) for assessing the quality of nonrandomised studies in meta-analyses. www.ohri.ca/ programs/clinical_epidemiology/oxford.asp (accessed prior to 15 November 2018).

\section{WHO 2012}

World Health Organization, Department of Reproductive Health and Research. Safe abortion: technical and policy guidance for health systems, second edition. www.who.int/reproductivehealth/publications/unsafe abortion/9789241548434/en/ (accessed prior to 15 November 2018).

\section{WHO 2017}

World Health Organization. Consolidated Guidelines on Sexual and Reproductive Health and Rights of Women Living With HIV Geneva: World Health Organization, 2017.

\section{World Bank 2017}

World Bank. World Development Indicators 2017. Washington, DC: World Bank. License: Creative Commons Attribution CC BY 3.0 IGO, 2017. 
CHARACTERISTICS OF STUDIES

Characteristics of included studies [ordered by study ID]

Posokhova 2012

\begin{tabular}{ll}
\hline Methods & Prospective cohort study using clinical data reported in a conference abstract \\
\hline Participants & 68 women living with HIV who underwent medical abortion \\
\hline Interventions & $\begin{array}{l}\text { Mifepristone } 200 \mathrm{mg} \text { orally in hospital setting followed by home self administration of misoprostol } 400 \\
\text { mcg sublingually for medical abortion up to } 63 \text { days amenorrhea }\end{array}$ \\
\hline Outcomes & $\begin{array}{l}\text { Efficacy (complete abortion); adverse medical events (incomplete abortion, heavy bleeding, continued } \\
\text { pregnancy, serious infection) }\end{array}$
\end{tabular}

\section{Notes}

\section{Risk of bias}

\begin{tabular}{lll}
\hline Bias & Authors' judgement & Support for judgement \\
\hline $\begin{array}{l}\text { Random sequence genera- } \\
\text { tion (selection bias) }\end{array}$ & Unclear risk & $\begin{array}{l}\text { This was not a randomized controlled trial. Participants were not randomized } \\
\text { to receive home administration of misoprostol for medical abortion. }\end{array}$ \\
\hline $\begin{array}{l}\text { Allocation concealment } \\
\text { (selection bias) }\end{array}$ & Unclear risk & There was no control or comparison group. \\
\hline $\begin{array}{l}\text { Blinding of participants } \\
\begin{array}{l}\text { and personnel (perfor- } \\
\text { mance bias) } \\
\text { All outcomes }\end{array}\end{array}$ & Unclear risk & $\begin{array}{l}\text { Due to the nature of the intervention and the study design, participants were } \\
\text { not blinded. }\end{array}$ \\
\hline
\end{tabular}

\begin{tabular}{|c|c|c|}
\hline $\begin{array}{l}\text { Blinding of outcome as- } \\
\text { sessment (detection bias) } \\
\text { All outcomes }\end{array}$ & Unclear risk & $\begin{array}{l}\text { Due to the nature of the intervention and the study design, outcome assess- } \\
\text { ment was not blinded. }\end{array}$ \\
\hline
\end{tabular}

\begin{tabular}{lll}
\hline $\begin{array}{l}\text { Incomplete outcome data } \\
\text { (attrition bias) } \\
\text { All outcomes }\end{array}$ & Unclear risk & No reports or description of incomplete data in study report \\
\hline $\begin{array}{l}\text { Selective reporting (re- } \\
\text { porting bias) }\end{array}$ & Unclear risk & Not applicable due to study design \\
\hline Other bias & Low risk & $\begin{array}{l}\text { Unclear from study report how researchers confirmed that participants fol- } \\
\text { lowed instructions for home administration of misoprostol }\end{array}$ \\
\hline
\end{tabular}

Characteristics of excluded studies [ordered by study ID]

\begin{tabular}{ll}
\hline Study & Reason for exclusion \\
\hline Agwu 2011 & Did not report on abortion outcomes \\
\hline Ammassari 2013 & Did not report on abortion outcomes \\
\hline Birungi 2011 & Did not report on abortion outcomes; conducted in Kenya where abortions are restricted \\
\hline \hline
\end{tabular}




\begin{tabular}{|c|c|}
\hline Study & Reason for exclusion \\
\hline Blanchard 2012 & Review article; no original data presented \\
\hline Blood 2009 & Did not report on abortion outcomes \\
\hline Coll 2011 & Did not report on abortion outcomes \\
\hline Grubert 2002 & $\begin{array}{l}\text { Examined postoperative complications following obstetric and gynecological surgical procedures, } \\
\text { including curettage, among women living with HIV and women without HIV }\end{array}$ \\
\hline Mitchell 2010 & Did not report on HIV status of women \\
\hline Okong 2002 & Abortions are restricted in Uganda; the abortion procedure was unknown. \\
\hline Othieno 2015 & Abortions are restricted in Uganda; the abortion procedure was unknown. \\
\hline Para 2010 & $\begin{array}{l}\text { Focused on the anti-HIV activity of mifepristone; did not examine surgical or medical abortion; not } \\
\text { limited to women-only } 1 \text { woman out of the } 57 \text { total participants }\end{array}$ \\
\hline Pongsatha 2011 & $\begin{array}{l}\text { Misoprostol-induced abortion outcomes were not stratified by HIV status. Out of the } 741 \text { total abor- } \\
\text { tions examined in the study, only } 4 \text { were among HIV-positive women. }\end{array}$ \\
\hline Stuart 2004 & $\begin{array}{l}\text { Examined morbidity associated with curettage for the management of both spontaneous and in- } \\
\text { duced abortions between women living with HIV and women without HIV in the USA. Results were } \\
\text { not stratified by type of abortion (spontaneous vs induced). }\end{array}$ \\
\hline
\end{tabular}

\section{A P PE N D I CES}

\section{Appendix 1. CENTRAL (Cochrane Register of Studies Online (CRSO)) search strategy}

Web platform

Searched from inception to 17 April 2018

\#1MESH DESCRIPTOR Abortion, Induced EXPLODE ALL TREES 962

\#2abort*:TI,AB,KY 3862

\#3(terminat* adj3 pregnan*):TI,AB,KY 716

\#4(menstrual regulation):TI,AB, KY 12

\#5\#1 OR \#2 OR \#3 OR \#4 4065

\#6MESH DESCRIPTOR HIV Infections EXPLODE ALL TREES 8345

$\# 7$ (immunodeficiency syndrome*):TI,AB,KY 1381

\#8(human immunodeficiency):TI,AB, KY 7192

\#9(human t cell ${ }^{\star}$ ):TI,AB,KY 83

\#10HIV:TI,AB,KY 14305

\#11(immunodeficiency virus ${ }^{\star}$ ):TI,AB,KY 7197

$\# 12$ (acquired immune deficiency):TI,AB,KY 609

\#13(immun* deficiency syndrome ${ }^{\star}$ ):TI,AB, KY 676

\#14(Acquired Immunodeficienc ${ }^{\star}$ ):TI,AB,KY 1386

\#15(T-Lymphotropic Virus Type III):TI,AB,KY 0

\#16AIDS:TI,AB,KY 6092

\#17\#6 OR \#7 OR \#8 OR \#9 OR \#10 OR \#11 OR \#12 OR \#13 OR \#14 OR \#15 OR \#16 17864

\#18\#5 AND \#17 42

\section{Appendix 2. MEDLINE search strategy}

Ovid platform 
Searched from 1946 to 17 April 2018

1 exp Abortion, Legal/ or exp Abortion, Induced/ (40558)

2 exp Abortion, Therapeutic/ (5391)

3 abort $^{\star}$.tw. (75625)

4 (terminat ${ }^{\star}$ adj3 pregnan*).tw. (12981)

5 menstrual regulation.tw. (245)

6 or/1-5 (98759)

7 exp HIV-2/ or exp HIV/ or exp HIV-1/ (97097)

8 exp Acquired Immunodeficiency Syndrome/ (79169)

9 immunodeficiency syndrome*.tw. (17552)

10 human immunodeficiency.tw. (84841)

11 human $t$ cell leukemia.tw. (3925)

12 human $t$ cell lymphotropic.tw. (2237)

13 HIV.tw. (295259)

14 immunodeficiency virus ${ }^{\star}$.tw. (88989)

15 acquired immune deficiency.tw. (6032)

16 immun* deficiency syndrome*.tw. (6325)

17 Acquired Immunodeficienc*.tw. (17012)

18 T-Lymphotropic Virus Type III.tw. (255)

19 AIDS.tw. (145241)

20 or/7-19 (415164)

21 exp animals/ not humans.sh. (4742231)

226 and 20 (1792)

2322 not 21 (1742)

\section{Appendix 3. Embase search strategy}

Ovid platform

Searched from 1980 to 17 April 2018

1 exp HIV-2/ or exp HIV/ or exp HIV-1/ (172720)

2 immunodeficiency syndrome*.tw. (17564)

3 human immunodeficiency.tw. (87299)

4 human $t$ cell leukemia.tw. (4219)

5 human t cell lymphotropic.tw. (2455)

6 HIV.tw. (343988)

7 immunodeficiency virus ${ }^{\star}$. tw. (91497)

8 acquired immune deficiency.tw. (6182)

9 immun* deficiency syndrome*.tw. (6474)

10 Acquired Immunodeficienc*.tw. (16863)

11 T-Lymphotropic Virus Type III.tw. (241)

12 AIDS.tw. (155041)

13 exp acquired immune deficiency syndrome/ (136832)

14 or/1-13 (498686)

15 exp induced abortion/ or exp medical abortion/ or exp abortion/ or exp surgical abortion/ or exp therapeutic abortion/ (93038)

16 abort*.tw. (76014)

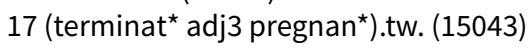

18 menstrual regulation.tw. (168)

19 or/15-18 (133298)

2014 and 19 (2372)

21 (exp animal/ or animal.hw. or nonhuman/) not (exp human/ or human cell/ or (human or humans).ti.) (5920370)

2220 not 21 (2288)

\section{Appendix 4. PsycINFO search strategy}

Ovid platform

Searched from 1806 to 17 April 2018

1 exp INDUCED ABORTION/ (2462)

2 abort*.tw. (6275)

3 (terminat $^{\star}$ adj3 pregnan*).tw. (776)

Medical and surgical abortion for women living with HIV (Review) 
4 menstrual regulation.tw. (5)

5 or/1-4 (6764)

6 exp HIV/ (39020)

7 exp AIDS/ (14873)

8 immunodeficiency syndrome ${ }^{*}$.tw. (765)

9 human immunodeficiency.tw. (5857)

10 HIV.tw. (46934)

11 AIDS.tw. (36124)

12 acquired immune deficiency.tw. (3103)

13 Acquired Immunodeficienc ${ }^{\star}$.tw. (757)

14 or/6-13 (63605)

155 and 14 (289)

\section{Appendix 5. CINAHL search strategy}

\section{EBSCO platform}

Searched from 1961 to 17 April 2018

\begin{tabular}{|c|c|c|}
\hline \# & Query & \\
\hline S47 & S20 AND S46 & 413 \\
\hline S46 & S33 OR S45 & $1,784,883$ \\
\hline S45 & $\begin{array}{l}\text { S34 OR S35 OR S36 OR S37 OR S38 OR S39 OR S40 OR S41 OR S42 OR S43 OR } \\
\text { S44 }\end{array}$ & $1,175,848$ \\
\hline S44 & TX allocat* random* & 7,415 \\
\hline S43 & (MH "Quantitative Studies") & 16,662 \\
\hline S42 & (MH "Placebos") & 10,451 \\
\hline S41 & TX placebo* & 48,143 \\
\hline S40 & TX random* allocat* & 7,415 \\
\hline S39 & (MH "Random Assignment") & 44,556 \\
\hline S38 & TX randomi ${ }^{\star}$ control $^{\star}$ trial $^{\star}$ & 134,734 \\
\hline S37 & 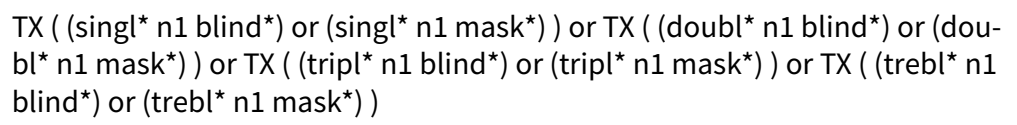 & 917,459 \\
\hline S36 & 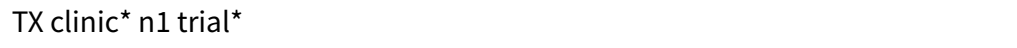 & 213,744 \\
\hline S35 & PT Clinical trial & 81,330 \\
\hline S34 & (MH "Clinical Trials+") & 224,611 \\
\hline S33 & $\begin{array}{l}\text { S21 OR S22 OR S } 23 \text { OR S24 OR S25 OR S26 OR S } 27 \text { OR S28 OR S } 29 \text { OR S } 30 \text { OR } \\
\text { S31 OR S } 32\end{array}$ & 774,996 \\
\hline S32 & TX observational & 52,761 \\
\hline
\end{tabular}


(Continued)

\begin{tabular}{|c|c|c|}
\hline S31 & (MM "Observational Methods") & 440 \\
\hline S30 & TX survey & 256,573 \\
\hline S29 & (MM "Surveys") & 4,946 \\
\hline S28 & (MM "Prevalence") & 1,980 \\
\hline S27 & TX cross sectional & 155,717 \\
\hline S26 & (MM "Cross Sectional Studies") & 168 \\
\hline S25 & TX retrospective & 207,075 \\
\hline S24 & TX longitudinal & 68,012 \\
\hline S23 & TX cohort & 132,118 \\
\hline S22 & $\begin{array}{l}\text { (MM "Prospective Studies") OR (MH "Concurrent Prospective Studies") OR (MH } \\
\text { "Nonconcurrent Prospective Studies") }\end{array}$ & 1,349 \\
\hline S21 & $\begin{array}{l}\text { (MH "Case Control Studies+") or (MH "Control Group") or (MH "Matched-Pair } \\
\text { Analysis") or (TI (case or cases) n5 TI (control or controls)) OR (AB (case or cas- } \\
\text { es) n5 AB (control or controls)) OR (TI (case or cases) n3 TI (matched)) OR (AB } \\
\text { (case or cases) n3 AB (matched)) OR TI (control group*) }\end{array}$ & 84,748 \\
\hline S20 & S5 AND S19 & 780 \\
\hline S19 & $\begin{array}{l}\text { S6 OR S7 OR S8 OR S9 OR S10 OR S11 OR S12 OR S13 OR S14 OR S15 OR S16 OR } \\
\text { S17 OR S18 }\end{array}$ & 127,276 \\
\hline $\mathrm{S} 18$ & TX AIDS & 78,946 \\
\hline S17 & TX T-Lymphotropic Virus Type III & 17 \\
\hline S16 & TX Acquired Immunodeficienc ${ }^{\star}$ & 15,547 \\
\hline S15 & TX immun* deficiency syndrome ${ }^{\star}$ & 1,846 \\
\hline S14 & TX acquired immune deficiency & 825 \\
\hline S13 & TX immunodeficiency virus ${ }^{\star}$ & 14,136 \\
\hline $\mathrm{S} 12$ & TX HIV & 93,911 \\
\hline S11 & TX human $\mathrm{t}$ cell lymphotropic & 110 \\
\hline S10 & TX human t cell leukemia & 85 \\
\hline S9 & TX human immunodeficiency & 14,151 \\
\hline S8 & TX immunodeficiency syndrome* & 15,601 \\
\hline S7 & $\begin{array}{l}\text { (MM "Human Immunodeficiency Virus+") OR (MM "Acquired Immunodeficiency } \\
\text { Syndrome") }\end{array}$ & 13,984 \\
\hline
\end{tabular}


(Continued)

\begin{tabular}{lll} 
S6 & (MM "HIV Infections+") OR (MM "HIV-Infected Patients+") OR (MM "HIV-1") \\
\hline S5 & S1 OR S2 OR S3 OR S4 & 16,291 \\
\hline S4 & TX menstrual regulation & 45 \\
\hline S3 & TX terminat* N3 pregnan* & 2,232 \\
\hline S2 & TX abort* & 15,239 \\
\hline S1 & (MM "Abortion, Induced+") \\
\hline
\end{tabular}

\section{Appendix 6. Trials registries search strategy}

From inception to present

Web platforms

"HIV AND abortion"; "AIDS AND abortion"

\section{CONTRIBUTIONS OF AUTHORS}

HTS developed the initial protocol, screened and assessed records for inclusion in the review, drafted the review manuscript, edited the manuscript draft, and approved the final manuscript.

MN developed the initial protocol with critical feedback on the protocol provided by HTS, provided critical feedback on the manuscript draft, and approved the final manuscript.

BG developed the initial protocol with critical feedback on the protocol provided by HTS, provided critical feedback on the manuscript draft, and approved the final manuscript.

CEK developed the initial protocol with critical feedback on the protocol provided by HTS, screened and assessed records for inclusion in the review, drafted the review manuscript, edited the manuscript draft, and approved the final manuscript.

\section{DECLARATIONS OF INTEREST}

HTS has no conflict of interest to declare.

MN has no conflict of interest to declare.

BG has no conflict of interest to declare.

CEK has no conflict of interest to declare.

The opinions or assertions contained herein are private ones of the authors and are not to be construed as official or reflecting the views of their respective institutions.

\section{SOURCES OF SUPPORT}

\section{Internal sources}

- World Health Organization, Department of Reproductive Health and Research, Switzerland.

Funding

\section{External sources}

- None, Other.

\section{DIFFERENCES BETWEEN PROTOCOLANDREVIEW}

We updated the Background section. 


\section{NOTES}

Not applicable.

\section{IN DEX TERMS}

\section{Medical Subject Headings (MeSH)}

*Abortifacient Agents, Nonsteroidal [administration \& dosage]; *Abortifacient Agents, Steroidal [administration \& dosage]; *HIV LongTerm Survivors; *Mifepristone [administration \& dosage]; *Misoprostol [administration \& dosage]; Abortion, Induced [adverse effects] [*methods]; Administration, Oral; Administration, Sublingual; Drug Administration Schedule; Prospective Studies

\section{MeSH check words}

Adult; Female; Humans 